Priestley, M. \& Philippou, S. (2019). Curriculum is - or should be - at the heart of educational practice, The Curriculum Journal, 30:1, 1-7, DOI: $10.1080 / 09585176.2019 .1598611$

\title{
Editorial Curriculum is - or should be - at the heart of educational practice
}

We write our first Editorial as Lead Editors of The Curriculum Journal against the political backdrop of turbulent scenes in the UK Parliament. On 12 March 2019, Members of Parliament voted (for a second time) to categorically reject the Prime Minister's 'deal' for exiting the European Union. The following day, they voted almost as decisively to reject a 'no deal' exit from the EU. Despite this, at the time of writing it is still quite possible that the UK is spiralling inexorably towards a chaotic (some would say catastrophic) no deal Brexit, with long term effects on the prosperity and wellbeing of its citizens, on its future trading relations with the rest of the world, and ultimately upon its international standing and reputation.

The reasons for Brexit are complex and contested, and must be seen in the context of global trends that are leading to similar turbulence in other settings. These include the rise of populist politics and right-wing extremism, fuelled by fake news, conspiracy theories and (allegedly) manipulation of social media for political gain by malign foreign powers. What is certain in this messy situation is that life for many people is becoming increasingly uncertain in layered and entangled contexts of economic instability, environmental challenges and wars over resources. Complexity, austerity and precarity are hallmarks of modern states, creating the conditions where political dissonance and social unrest might thrive. National governments, for all of their efforts to steer their economies and societies, are buffeted by both local and transnational forces that are often beyond their control. Paradoxically, a potential solution to these issues - transnational cooperation through bodies such as the EU is itself a casualty of these very same forces. Brexit is, of course, a contemporary manifestation of this phenomenon.

As modern democracies struggle for legitimacy within, across and beyond national boundaries, education seems to be yet again expected to provide quick and easy solutions; school curricula and higher education programmes of study in particular are construed as spearheading such 'problem-solving' efforts. National curricula as official-to-beimplemented texts have often been conceptualised in utilitarian terms, rendering them sites of acute contestation, as different social actors (academic, political, social, economic, educational-institutional and others) assert and negotiate their power towards diverse agendas of curricular purpose.

While we would not wish to claim that education - and especially schooling - is the magic bullet to address these dilemmas and problems, it is nevertheless the case that education is a vital component in efforts to both create better and more cohesive societies, and to address the economic, social and environmental conditions that potentially destabilise modern societies. This has been widely recognised. For example the OECD, in a recent discussion paper (2018), has identified the important role of education in addressing a number of challenges. The first of these is identified as environmental, for example climate change and degradation of natural resources. The second is economic, for instance creating inclusive and sustainable economic models that do not marginalise whole populations. The third challenge is social, for example dealing constructively with issues relating to migration and increasing social diversity. Underpinning all of this is the need for educational systems that develop knowledge and understanding of the complex worlds - social and natural - inhabited by diverse populations, and which go beyond a narrow focus on the development of competencies. 
There is nothing new, of course, in the trend towards centralised regulation of education systems to address wider social and economic imperatives. Governments through the ages have sought to instrumentalise education, although in recent decades this trend has become more systematic worldwide, as policy discourses migrate and are cherry-picked from one setting to be used in other (Rizvi \& Lingard, 2010). For example, Smyth and Shacklock, writing in the 1990s, pointed to the "worldwide move towards recentralising control through national curricula, testing, appraisal, policy formulation, profiling, auditing and the like, while giving the impression of decentralisation' (1998, p.20). Moreover, many writers have noted the shift, in the 1980s and 1990s away from educational discourses and their replacement by the language of business and management. For example, according to Arnold, 'conspicuously absent .... is an engagement with traditional educational discourses - learning theory, curriculum theory, pedagogy and so forth - all seem be irrelevant to the reformulation now underway' (1996, p. 226).

These trends have accelerated since the turn of the millennium. New forms of national curriculum emerging worldwide have shifted the focus from input regulation - detailed specification of content to be taught - to output regulation - evaluation of the outputs of education, gauged via analysis of attainment data and by school inspections (Nieveen \& Kuiper, 2012). This 'new curriculum' (Biesta \& Priestley, 2013) continues the trend of positioning education systems more widely, and curriculum in particular, as drivers of economic development and national competitiveness (Yates \& Young, 2010). The 'new curriculum' is characterised a number of common features, albeit with local variation in different national contexts. These include: a shift from the prescriptive specification of knowledge content evident in many earlier national curricula to what Young (2008) has termed genericism; a new focus on the centrality of the learner, accompanied by the development of active forms of pedagogy and a view of teachers as facilitators of learning (Sinnema \& Aitken, 2013); and the articulation of curriculum as assessable outcomes, modular courses and ladders of qualifications (Young, 2008), accompanied by increasingly pervasive regimes of accountability and cultures of performativity (Jeffrey \& Troman, 2012).

In the light of these international trends in education, systematic and nuanced thinking about the curriculum has never been more important. The curriculum is - or at least should be - at the heart of educational discourse and practice. Moreover, the role of scholarly journals, such as the Curriculum Journal, with a specialist focus on curriculum studies is key to developing and maintaining this. It is therefore with a great sense of responsibility and pride that we take on the editorship of a journal with an illustrious and distinctive history, and with a strong track record of making important contributions to scholarship, research and practice in the field of curriculum. The new editorial team comprises two Lead Editors, Mark Priestley (University of Stirling, UK) and Stavroula Philippou (University of Cyprus), and an extended international team of Associate Editors:

- Daniel Alvunger - Linnaeus University, Sweden

- Kathy Hibbert - Western University, Canada

- David Leat - Newcastle University, UK

- Nienke Nieveen - University of Twente, Netherlands

- Claire Sinnema - University of Auckland, NZ

- Tiina Soini - Tampere University

Additionally, Joe Smith (University of Stirling) has taken on the role of Reviews Editor. 
Definitions of 'curriculum' as a concept of inquiry and 'curriculum studies' as an interdisciplinary field have repeatedly been addressed in the literature through the metaphor of boundaries - disciplinary and in other forms. In a sense, a key task occupying a journal especially one of the few and key journals in a particular field - relates to the paradoxical task of maintaining and even consolidating those boundaries, while simultaneously contributing to understanding, challenging and reshaping them. The Curriculum Journal has over the years focused on, and will continue to focus on, curriculum theory, policy and practice, including research on issues concerning curriculum structure, organisation and development, teaching, learning, pedagogy and assessment. All of these issues comprise the multi-layered social practices through which curriculum is made - planned, structured, enacted, evaluated and lived. As these issues conceivably relate to a wide range of subjectbased or thematic areas in a range of levels or sites of curriculum-making across local, national, international and transnational contexts, involving a wide range of social actors (as individuals and as bodies/institutions) across time and space, it is already apparent that the complexity and diversity of the field, as it has been historically shaped, will continue to present us with challenges. In what follows, we set out some of the parameters that at the moment seem to frame our task.

We view curriculum research and scholarship as currently being at a critical juncture. In the UK, after much activity and productivity in the 1970s and 1980s, it became negatively influenced by the introduction of the National Curriculum, becoming primarily geared towards questions of fidelity of implementation and normative evaluation of the National Curriculum. In recent years we have seen strong signs of a revival of interest in curriculum matters that go beyond these questions. Curriculum discourse, so often seemingly absent from educational conversations in the UK, is once more apparent, for example, in the public pronouncements of Ofsted in England. These trends are evident more broadly. In many countries, the curriculum has become a central core of education policy, manifested in recent years in the development of new and innovative forms of national curriculum policy and a renewed emphasis on the important role of teachers as curriculum makers (for example, the Welsh Successful Futures initiative, the New Zealand Curriculum and Curriculum.nu in the Netherlands). These trends are to be welcomed, but come with considerable challenges, not least in supporting and sustaining the capacity of professionals to conceptualise, mediate and enact the curriculum in educational institutions such as schools. Furthermore, such attention to curriculum has sometimes contributed to its constriction, as official curricular texts and policies have been framed as tools of regulation and control, both of teachers' work and of pupil learning, with a strong focus on standardised or high-stakes testing. The increased focus on teachers and the curriculum is clearly related to school development and questions about how different models of continuing professional education become a vehicle to facilitate teachers' curriculum practice at school and classroom level. To some extent, it has also found its way into discussions about initial teacher education.

This increased professional interest in curriculum is paralleled by increasing activity and interest within academic circles. In Europe, for example, the EERA Network 3 Curriculum has markedly enhanced its profile, and the formation of the European Association for Curriculum Studies has been followed by well attended conferences and considerable international networking since 2013. These are hopeful signs, but also signal the need to enhance and reinforce the value and credibility of curriculum scholarship and research, especially amongst end users and the international organisations, such as the OECD, which are so influential in shaping educational discourse in today's world. 
Internationally, significant parallel developments greatly add to the complexity of the curriculum field. In North America, the 'reconceptualisation' of curriculum studies over recent decades, and subsequent concerns over 'internationalisation' and 'postreconceptualisation', have shifted the focus to some extent from questions of curriculum structure, organisation, development and enactment towards wider historical, sociological and political questions about the curriculum. On the European continent, the concept of 'curriculum' has been less prominent as a field or object of scholarship and research, than has been the case in the Anglophone sphere; instead questions about the curriculum have been approached more through the traditions of 'bildung' and 'didactics'. Important questions about the interconnections between didactics and curriculum have long engaged curriculum scholars across the Atlantic.

We see the Curriculum Journal as an important forum for these debates. This belief is reflected in the synthesis of the editorial team, which brings together curriculum scholars from across Europe, as well as Canada and New Zealand. The editorial team's studies, teaching and research encompass the complex landscape of curriculum studies and aim at contributing to its ongoing formation, by providing a publishing space wherein difficult curriculum questions can be asked and debated from different perspectives, including questions about whom curriculum research is for and what counts as curriculum research. We perceive our role as enablers of such debates within the space provided by the journal, and the papers included in this issue indeed focus around crucial and difficult curriculum questions.

The first three papers directly explore the tensions and opportunities in Citizenship Education and History, subject areas which have traditionally been designed to inculcate certain kinds of identities, subjectivities, and embodied selves of modern national citizens. As the first mass school curricula were historically mobilised to construct a sense of modern national identity (Green, 1997; Popkewitz, 2007), maintain power relations, and reorganise the relationship between a capitalist economic formation, the state, and its citizen-subjects (Mitchell, 2003), such school subjects were strongly construed as fueling such purposes. They are therefore at present open to challenge, as late-modernity has rendered the national as contested (from with-in and from with-out), or at least as already and simultaneously global. Curricular agendas have been re-energised to fuel national identities as 'both reaction to and strategy for global challenges, as well as to develop new dispositions for globalising fields. The first is the centripetal project of re-nationalising the social imaginary and the second is the equal but opposite centrifugal project of de-nationalising the social imaginary (Doherty, 2014, p. 177). These tensions are directly taken up in these three papers in ways that explore the pedagogical potential of what on first appearance might seem as historicised curricular impasses or impossibilities.

In their paper entitled "Decentring the 'places' of citizens in national curriculum: the Australian History curriculum" Kelsey Halbert and Peta Salter locate their argument on History amidst international debates about the production of curriculum texts and the epistemologies underpinning the knowledge legitimated in national curricula. Such debates tend to pull in different directions across various subject-areas; History curricula are caught between contradictory forces: 'coherent and unifying national narratives that are inclusive' and 'the complexity of the discipline and historical consciousness of the nation to which they are bound'. Using critical spatial theory, Halbert and Salter discuss the 'spaces' and 'places' of the Australian Curriculum History (Years 7-10), which they view as organising and 
disorganising 'representations of identities in and out of the centre of the national narrative'. By interrogating the impact of these representations within purported inclusive and cohesive national narratives, the authors draw attention to the notions of belonging presented to Australian citizens. They argue that resistance to normative national narratives and colonial legacies presented with place-based identities can reinhabit the curriculum through a decentring, which 'seeks to engage History students with alternative perspectives and articulations to the national narrative, and foster meaningful connections to place and citizenship'. The authors conclude by suggesting Critical Place-Based Education (PBE) as an appropriate pedagogy, which invites 'an embodied local/global citizen through local and marginalised knowledges' and 'seeks to blur and reinhabit the boundaries between dominant and marginalised spaces to imagine more nuanced articulations of citizenship in Australian Curriculum History'.

In "Australian schools as deliberative spaces: framing the goal of active and informed citizenship", Sarah Sorial and Andrew Peterson also mobilise the notion of 'space', albeit at the meso-level of the school, to address weaknesses in translating into practice Australian curricular goals of active and informed citizenship and of engaging with others in deliberative talk. They thus explore the value of deliberative democracy as a frame for active and informed citizenship by 'viewing schools as deliberative spaces which do/could engage in deliberative pedagogies' as 'a useful and focused basis for conceiving how young Australians do and can engage in, and learn, the capacities necessary for democratic citizenship'. The authors distance themselves from more generalised notions of 'responsible', 'active' and 'critical' and reject the neo-liberalisation of active citizenship, suggesting that deliberative democracy needs to be done/developed rather than assumed. They consider schools as such doing spaces, wherein 'deliberative capacities can be developed through the design of deliberative spaces'. To argue this point they draw on 'existing empirical studies to illustrate a key feature central to schools as deliberative spaces, namely deliberative pedagogies'; and they unpack the knowledge, skills and dispositions which could be developed within schools as deliberative spaces.

Andrew Mansfield, in his paper entitled "Confusion, contradiction and exclusion: the promotion of British values in the teaching of history in schools", discusses the introduction of 'British values', set out by the Department for Education in England, arguing that they are 'confusing, contradictory, and appear to exclude a sizeable minority of pupils of minority backgrounds from the current historical narrative of Britain as delineated by the National Curriculum (2013)'. The curriculum elicited considerable controversy by mandating promotion of fundamental values, designated as British, as part of Spiritual, Moral, Spiritual and Cultural development of pupils in schools. The tensions the author brings forth are a fine example of the tensions amidst which national curricula in general and history curricula in particular can become caught, as more academic rationalist purposes are contradicted or undermined by sometimes questionable social and moral purposes (values) to be unquestionably pursued by teachers. The author brings a unique biographical perspective, as a former academic who has moved into secondary teaching, to discuss the challenges with which new teachers are presented, since there is little advice on what these values are, or how they are to be taught.

Issues of citizenship are entwined with issues of knowledge, often contested. The above three papers address disciplinary/epistemological issues, arising from the academic fields of History and Political Science when knowledge questions are re-contextualised in/for school settings. The next paper in this issue again focuses on knowledge. In this case, the knowledge 
question is taken up by Lyn Yates, Larissa McLean Davies, Lucy Buzacott, Brenton Doecke, Philip Mead and Wayne Sawyer in their article entitled "School English, literature and the knowledge-base question". The authors explore what changes within a disciplinary academic field, 'literary studies', may mean for teaching and teacher education agendas, when recontextualised as the study of literature within English, a subject with a turbulent sociopolitical past within Australia as a former settler colony. Rather than drawing on conversations within the field of English, wherein 'the selection of texts and form of study of literature within the English curriculum has long been an area of controversy', the authors locate their standpoint within the context of 'current waves of curriculum reform ... to raise questions about the knowledge agenda, and the knowledge-base agenda for teaching and teacher education'. Without assuming a particular position on knowledge in this area, and by taking the Australian Curriculum and standards for teacher registration as a context, the authors raise broader questions around knowledge for researchers and teacher education. They illustrate how important questions of what knowledge-base teachers are expected to bring to their work are elided both in current regulations and debates, and in research on 'good teaching' in this area. This gap is amplified by how 'literary studies (as a discipline or university major) is itself an unstable and changing field'. This in turn fuels the key question the authors address: what kind of knowledge does a good English teacher bring to their work?

In his paper "Novelty and educational experience", Benjamin C. Ingman turns our attention to instances when/where knowledge of worth is to be found not only outside disciplinary/academic boundaries or even schooling, but also in experiences characterised by the unknown, by unpredictability and by novelty, as framed by "Adventure Education" (AE). Using the method of educational criticism and connoisseurship, the author interviewed and observed 41 participants of AE programmes. As novelty emerged as a central quality of the experiences of the participants, the author revisits conceptions of educational philosophy that 'contend for the virtue of novelty, as well as those that focus on a quality in tension with novelty, continuity'. He thus discusses the potential educational value of novelty, relating it to different conceptions of educational experience and offering implications for schooling to 'entertain the notion that educational virtue exists outside the school', thus rendering it valuable to look for and learn from it. In doing so, he returns to and contributes to pragmatist theorisations of curriculum that are over a century-old, and urges us to further consider students' perspectives on education.

This issue includes three reviews of books. In reviewing "A literature of questions: nonfiction for the critical child" (by Joe Sutliff Sanders), Farrar welcomes how children's nonfiction, as one of the monoliths of children's literature, is problematised by the author to shift traditional understandings thereof as authentic and valid/credible literature to a 'literature of questions', pregnant with pedagogical potential when certain theoretical principles are taken up. These include: the tension between perspectives that privilege 'answers' over 'questions' (or vice versa); the critical understanding that no text can be neutral or reliable, and the complex relationship between emotion and critical engagement. As Farrar notes, 'by extrapolating outwards from Sanders' focus on non-fiction, it is possible to see how his arguments connect to broader educational and cultural debates about fake news, for example, or the status of critical literacy, or even to conceptualisations of childhood and children as (critical) readers'.

Harsha Chandir considers a book edited by B. Maddox entitled "International Large-Scale Assessments in Education: Insider Research Perspectives". As a timely and aptly titled collection of 'insider' perspectives which brings to the fore 'the less publicised aspects of 
ILSAs, from their development processes to the ways in which they shape educational policy and practice'. By considering the multiple and often (so far) absent from the literature perspectives that the volume brings together, the review highlights the dangers of identifying quality indicators with quality itself, and a culture which values that which can be assessed, thus constricting the scope and marginalizing questions of purpose on education.

Finally, in reviewing Daniel Osborn's book entitled "Representing the Middle East and Africa in social studies education: Teacher discourse and otherness", Kumar examines how the study of six secondary school History teachers illustrates the complex and multifaceted ways in which the teachers' discourse not only challenged, but also perpetuated otherness with regard to the diverse populations of the Middle East and Africa. The author provides a rare analysis of classroom discourse on social studies classes, thus adding to as well as problematising existing research, which has largely focused on official curricula and textbooks rather than the lived experience of teachers and students.

\section{Mark Priestley \\ Stavroula Philippou \\ Lead Editors}

\section{References}

Arnold, M. (1996). The High Tech Fordist School. Interchange, 27, 225-50.

Doherty, C. (2014). Forging the heteroglossic citizen: Articulating local, national, regional and global horizons in the Australian Curriculum. Discourse: Studies in the Cultural Politics of Education, 35, 177-189.

Green, A. (1997). Globalization, the nation-state and education. Basingstoke, England: Macmillan.

Jeffrey, B. \& Troman, G. (Eds.) (2012). Performativity across UK education: Ethnographic cases of its effects, agency and reconstructions. Painswick: EandE Publishing.

Mitchell, K. (2003). Educating the national citizen in neoliberal times: From the multicultural self to the strategic cosmopolitan. Transactions of the Institute of British Geographers, 28(4), 387-403.

Nieveen, N. \& Kuiper, W. (2012). Balancing curriculum and freedom in the Netherlands. European Educational Research Journal, 11(3), 357-368.

OECD (2018). The Future of Education and Skills: Education 2030. Paris: OECD.

Popkewitz, T. S. (2007). Cosmopolitanism and the age of school reform: Science, education and making society by making the child. New York, NY: Routledge.

Priestley, M. \& Biesta, G.J.J. (Eds.) (2013). Reinventing the curriculum: New trends in curriculum policy and practice. London: Bloomsbury.

Rizvi, F. \& Lingard, R. (2010). Globalizing Education Policy. New York, NY: Routledge.

Sinnema, C. \& Aitken, G. (2013). Trends in International Curriculum Development. In M. Priestley \& G. J. J. Biesta (Eds), Reinventing the curriculum: New trends in curriculum policy and practice (pp. 141-164). London: Bloomsbury.

Smyth, J. \& Shacklock, G. (1998). Re-Making Teaching: ideology, policy and practice. London: Routledge.

Yates, L. \& Young, M. (2010). Editorial: globalization, knowledge and the curriculum. European Journal of Education, 45, 4-10.

Young, M. (2008). From Constructivism to Realism in the Sociology of the Curriculum. Review of Research in Education, 32, 1-28. 